\title{
EFFECTS OF THE BIODEGRADATION ON BIODEGRADABLE POLYMER BLENDS AND POLYPROPYLENE
}

\author{
R.C.T., Pereira* ${ }^{1,3}$, S. M. M., Franchetti ${ }^{a}$, J. A. M., Agnelli ${ }^{2}$, L.H.C., Mattoso ${ }^{3}$ \\ ${ }^{1}$ Department of Biochemistry and Microbiology, University State "Júlio de Mesquita Filho", UNESP, Rio \\ Claro, SP, Brazil \\ ${ }^{2}$ Department of Materials Engineering, Federal University of São Carlos, UFSCar, São Carlos, SP, Brazil \\ ${ }^{3}$ Embrapa Agricultural Instrumentation, CNPDIA/EMBRAPA, São Carlos, SP, Brazil
}

\begin{abstract}
The large use of plastics in the world generates a large amount of waste which persists around 200 years in the environment. To minimize this effect is important to search some new polymer materials: the blends of biodegradable polymers with synthetic polymers. It is a large area that needs an intensive research to investigate the blends properties and its behavior face to the different treatments to aim at the biodegradation. The blends used in this work are: some biodegradable polymers such as: poly(hydroxybutyrate) (PHB) and poly(e-polycaprolactone) ( $\mathrm{PCL}$ ) with a synthetic polymer, polypropylene $(P P)$, in lower concentration. These blends were prepared using an internal mixer (Torque Rheometer), and pressed. These films were submitted to fungus biotreatment. The films analyses will be carried out by Fourier Transform Infrared (FTIR), UV-Vis absorption (UV-Vis), Scanning Electronic Microscopy (SEM), DSC and TGA.
\end{abstract}

\section{INTRODUCTION}

From the last decade of 20th century one of the rapidly growing areas for the use of plastics is packaging. Convenience and safety, low price and good aesthetic qualities are the most important factors determining rapid growth in the use of plastics for manufacturing of packing. Recently, out of total plastic production, $41 \%$ is used in packing industries, and $47 \%$ of them is used for the packing of foodstuffs [1]. These are generally made from polyolefins (e.g. polypropylene (PP), polyethylene (PE)), polystyrene (PS), poly(vinyl chloride) (PVC), etc., are mostly produced from fossil fuels, consumed and discarded into the environment, ending up as spontaneously undegradable wastes. That means, amounting to $40 \%$ of packaging refuse, is practically eternal, and the question of what to do with plastics refuse is becoming a global environmental problem, Ray and Bousmina [1]. To minimize this effect is important to search some new polymer materials: the blends of biodegradable polymers with synthetic polymers. It is a large area that needs an intensive research to investigate the blends properties and its behavior face to the different treatments to aim at the biodegradation. The blends used in this work are: some biodegradable polymers such as: poly(hydroxybutyrate-co-valerate) (PHB-V) and poly(\&-polycaprolactone) (PCL) with a synthetic polymer, polypropylene (PP), in lower concentration. These blends were prepared using an internal mixer (Torque Rheometer), and pressed. These films were submitted to fungus biotreatment. The films analyses will be carried out by Fourier Transform Infrared (FTIR), UV-Vis absorption (UV-Vis), Scanning Electronic Microscopy (SEM), DSC and TGA.

\section{PROCEDURE}

In this work, the blends were prepared using biodegradable polymers such as PHB-V or PCL (80wt\%) and PP (20wt\%) (homopolymer and copolymer) as synthetic polymer in a internal mixer (Torque Rheometer) and pressed. The films obtained were submitted Biotreatment using Phanerochaete chrysosporium Burds for 4 months.

\footnotetext{
*Rejane Cristina Trombini Pereira - Department of Biochemistry and Microbiology, University State "Julio de Mesquita Filho", UNESP, Av. 24A, 1515 CEP 13506-900

Rio Claro-SP-Brazil e-mail: rejpereira@hotmail.com
}

\footnotetext{
CP1042, $I V^{\text {th }}$ International Conference on Times of Polymers (TOP) and Composites edited by D. Acierno, A. D'Amore, and L. Grassia

(C) 2008 American Institute of Physics 978-0-7354-0570-7/08/ $\$ 23.00$
} 


\section{RESULTS}

The Fig.1 presents SEM micrographs of the blends before and after biotreatment using Phanerochaete chrysosporium Burds for 4 months

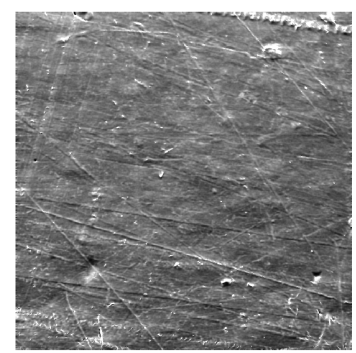

a)

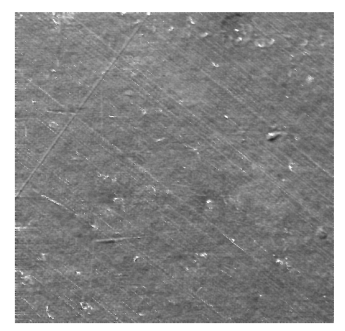

c)

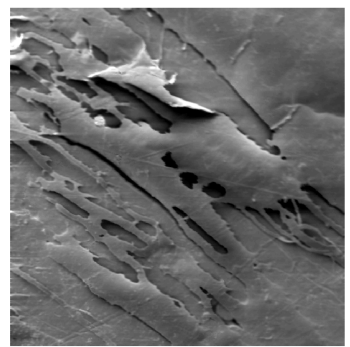

b)

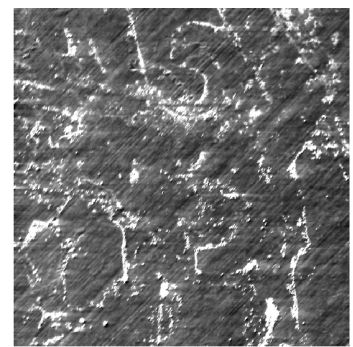

d)

Figure 1: SEM micrographs of blends a) PHB/PP (x200) and e) PCL/PP (x200), before the biotreatment and c) PHB/PP (x200), g) PCL/PP (x200) after biotreatment for 4 months.

\section{CONCLUSIONS}

Analysing the results of SEM we can note macrophasis morphological modifications. In the blends using PHB, as a biodegradable polymer, is possible to see degradation by layers. Results of FTIR provided us more informations about the structural changes after the biotreatment, for example, PCL presents these modifications between $1400-1000 \mathrm{~cm}^{-1}$. We also can see a variation to TG peaks to more high temperature after biodegradation for PHB-V/PP homopolymer blends and for PP homopolymer in the PCL/PP blends. We suppose that these variations in the temperature of the TG peaks can be because the modification in the crystallinity of these blends with the biotreatment. These results can be noted in the DSC analysis too. Other studies have been done about the biodegradation of these polymer blends and other kinds of polymers studied by our research group, Campos et al [2].

\section{ACKNOWLEDGEMENTS}

FAPESP, EMBRAPA-CNPDIA São Carlos-SP Brazil, Prof. Dr. Marco Aurélio De Paoli, Maria Luiza (UnespR. Claro-SP - Br), Lea (Unicamp -Campinas- SP-Br)

\section{REFERENCES}

1. Ray, S.S. and Bousmina M., Progress in Materials Science, 50, 962-1069, 2005.

2. Campos, A.; Martins-Franchetti, S.M.; Agnelli, J.A.M. Brazilian Journal of Microbiology, 34, Suppl. 1, 111-113, 2003. 
Copyright of AIP Conference Proceedings is the property of American Institute of Physics and its content may not be copied or emailed to multiple sites or posted to a listserv without the copyright holder's express written permission. However, users may print, download, or email articles for individual use. 